\title{
Culture-shaped Mental Models and the Governance of Innovation in Tourist Destinations - Comparative Evidence from Ecuador and Azerbaijan.
}

\author{
Arne Schuhbert* \\ Katholische Universität Eichstaett-Ingolstadt (Alemania) \\ Andrea Muñoz-Barriga** \\ Pontificia Universidad Católica del Ecuador (Ecuador) \\ Hannes Thees*** \\ Katholische Universität Eichstaett-Ingolstadt (Alemania)
}

\begin{abstract}
Destinations in Developing Countries often display shortages when it comes to the creation and use of new innovative knowledge, thus inhibiting their possibilities to unfold the potential of tourism as a means for sustainable regional development. Findings from tourism research increasingly point to the nature of tourism stakeholders' mindsets as an inhibiting factor in this regard. However, empirical evidence is scarce on the complex structure and (culture-shaped) development-processes of those mental models that form the basis of these mindsets. This comparative study of two regional destinations in both Azerbaijian and Ecuador presents a new qualitative approach, based on the GABEK semantic modelling technique, where latent and manifest forms of collective mental models are uncovered together with the cultural "traces" left by their formation-process. As a main result, intervention areas for a targeted "cultural engineering" are identified on the basis of the extracted mental models that may serve as a starting point for a more systemic governance of innovation in DC-destinations.
\end{abstract}

Keywords: Innovation; Destination Governance; Mental Models; Role of Culture; Ecuador; Azerbaijan.

Modelos mentales y la gobernanza de la innovación en los destinos turísticos: evidencia comparativa de Ecuador y Azerbaiyán.

Resumen: Los destinos en los países en desarrollo (PD) a menudo muestran debilidades en la creación de nuevos conocimientos innovadores para desentrañar el potencial del turismo como un medio del desarrollo regional sostenible. La investigación turística generalmente localiza un factor inhibidor en la naturaleza de la mentalidad de los actores del turismo pero la evidencia empírica es escasa. En el caso de dos destinos regionales en Azerbaiyán y Ecuador, este estudio comparativo presenta un nuevo enfoque cualitativo sobre la base de la técnica de modelado semántico GABEK para extraer formas latentes y manifiestas de modelos mentales colectivos, así como las "huellas" culturales dejadas por su proceso de formación. Como resul-tado principal, se identifican las áreas de intervención para una "ingeniería cultural" que pueden servir como punto de partida para una gobernanza más sistémica de la innovación en los destinos en PD.

Palabras Clave: Innovación; Gobernanza de destinos; Modelos mentales; Cultura; Ecuador; Azerbaiyán.

\section{Introduction}

Using tourism as an instrument for sustainable regional development is a very knowledge-intensive undertaking, echoing the beginning transformation of the whole sector into a knowledge-based global

* Katholische Universität Eichstaett-Ingolstadt (Alemania); E-mail: arne.schuhbert@hochschule-rhein-waal.de

** Pontificia Universidad Católica del Ecuador (Ecuador); E-mail: amunoz@puce.edu.ec; https://orcid.org/0000-0001-5685-5268

*** Katholische Universität Eichstaett-Ingolstadt (Alemania); E-mail: hannes.thees@ku.de 
system of high complexity (Trunfio \& Campana, 2019; see also Jafari, 2001). Despite of a focus on primarily practical research questions, a growing set of authors have recently acknowledged the multidimensional nature of tourism as an information-intensive ecosystem of cross-sectoral stakeholders and its repercussions for sustainable development at the local, regional, national and international level (Gretzel et al, 2015; Ozseker, 2018; Bachinger et al. 2020). The channeling of multispatial information-streams into valuable knowledge, empowering local stakeholders towards self-guided, holistic management of tourism as a catalyzer for ecologically, socially and economically sustainable development is critical - in particular in destinations from the developing world. This will be all the more true in a post-Corona future, where a recollection towards regionalization of value-chains, sectoral resilience and sustainable production is foreseeable - especially if the causal connection of the current pandemic crisis with the climate crisis should become common sense in the future Lawler et al. (2021).

In many cases, the processing of new information into knowledge and finally into sustainability innovations may demand or induce a series of massive disruptions in existing structures, processes, cognitive- and perceptional patterns of tourism system actors. The success of radical innovation, be it in the fields of societal problem-solving and sustainability (social innovation), new forms of e-participative governance or solutions driven by intelligent information technologies (smart innovations) i.a. depend on an appropriate collective mindset of destination stakeholders, enabling a proper absorption of external information and the creation of innovative knowledge in the local context (Döpfer et al., 2016; Volgger et al., 2017; Kofler et al., 2018). A growing set of studies suggest that the global tourism sector in general as the tourism sector in Developing Countries (DC) in particular lack essential requirements here, i.a. since the formation of culture-shaped mental models or mindsets can have an inhibiting effect on knowledge absorption (Fuchs \& Baggio, 2017; Schuhbert, 2018; 2021). This opens up the question: How do these established mindsets shape the disposition of destination actors to innovate (here: especially in the field of sustainability) and how can this disposition be proactively governed?

The present study contributes to this vital question through a comparative study, focusing on the innovation-critical role of mental models. To this end, this study follows the definition of Rook (2013, p.45), which describes the mental model as " $a$ concentrated, personally constructed, internal conception, of external phenomena (historical, existing or projected), or experience, that affects how a person acts". In their basic substance, mental models thus consist of hypotheses and theories about system-environment interactions (see 2.2.). As the construction of individual mental models is strongly shaped by social processes, not the least through the socio-cultural framework of a destination (Schuhbert, 2021a), this study will commit itself to the diagnosis of innovation-critical culture-shaped mental models (CMM). A comparative approach in the rural destinations of Napo (Ecuador) and Guba-Khachmaz (Azerbaijan) offers the chance to optimize objectivity in selecting analytical criteria for culture-based phenomena (Hofstede, 2001). It allows the rendering of parallel developments and differences in sustainable tourism from the perspective of two DC-destinations in different socio-cultural/geographical contexts and different phases of destination development.

\section{Literature-Review}

\subsection{Determinants of Destination Innovativeness}

Starting with Hjalagers (2010) initial works on the phenomenon of innovation in tourism, a growing set of studies has continuously expanded and integrated its fragmented picture into much needed conceptual models (Binder, 2017). In their recent integrative review on the existing literature, Trunfio \& Campana (2019) conceive a destination as a localized innovation system, where novelties emerge as a result of dynamic knowledge exchange between customers (Lejarraja \& Walkenhorst, 2007; Pechlaner et al., 2012), political-institutional actors, local firms/industries (Hjalager, 2010), local communities and DMOs (Destination Management Organisation) in their collective function as the core-actors and major co-creators of knowledge (Trunfio \& Campana, 2019). This "ecosystem" of actors (Schuhbert, 2021a) can reach geographically far beyond the local context and thus entails a wide range of relevant sources for complementary knowledge for any single actor (Schuhbert, 2021).

To finally source complementary knowledge, stable exchange relations need to be established that take over the transfer-media function, whereby the type (tacit or codified) and amount of knowledge transferred changes with spatial distance and relationship-character (Ozseker, 2018). At the local level, transfers of knowledge, even among competitors, often take place indirectly and partly unconsciously (tacit knowledge) through mutual observation and adaptation or through informal communication when the partners are spatially proximate to one another (Lejarraja \& Walkenhorst, 2007; Hjalager, 2010; Pechlaner \& Bachinger, 2010). With rising spatial distance (regional, national, transnational level), the role of external providers 
of codified knowledge is constantly increasing and is usually accompanied by higher importance of formal relationships (Fuchs \& Baggio, 2017). ICT (Information and Communication Technology) and Social Capital can serve here as coupled enabling platforms for the emergence of innovation as they allow identification and transfer of new complementary tacit and codified knowledge from these external sources via activated networks of different types and geographical scales (Schuhbert, 2021b). However, the location-binding of tourism activities ultimately grounds any destination-related network in its local context (Ozseker, 2018; Döpfer et al, 2016; Kofler et al., 2018).

The identification and transfer of complementary external knowledge constitute only two from an entire "set" of personal and organizational capabilities that together build up the innovativeness of a tourist destination (Roberts et al., 2012). Referencing the works of Nonaka \& Takeuchi (1995), Ozseker (2018) expands Trunfios \& Campanas (2019) conception with the idea of knowledge-conversion as the core mechanism to destination-based Organizational Learning (OL). Knowledge-conversion here basically refers to the integration and transformation of mental models (Binder, 2017):

While the above-mentioned transfer of explicit knowledge, a.k.a. technologies, and implicit knowledge, a.k.a. experience, skills or capabilities (see Nonaka \& Takeuchi, 1995), requires the capacity to attach new to existing knowledge of the same type directly, knowledge-conversion describes the integration of technologies and capabilities, resulting in a transformation of both. For Ozseker (2018), this conversion of specific tacit knowledge, usually available in abundance at the local level, qualifies as the actual dynamizer of innovation in the destination. This dynamic ideally unfolds as a sequential, level-spaning process, where local tacit knowledge is constantly converted into and combined with explicit, codified knowledge from a variety of external sources, thus activating new exchange-relations from the local over the national to the international level and constantly creating innovative-knowledge, thus constantly competencies (Fischer, 2009; Pechlaner et al., 2014; Schuhbert, 2021).

The complex set of capabilities required for identifying, transferring, converting, and using external knowledge, a.k.a. absorptive capacity, overlaps conceptually with the organizational learning-capabilities. While its conceptual integration is still subject to the theoretical discussion, a growing number of studies plead for an extensive congruence (Schuhbert, 2021). Based on Roberts et al. (2012), the set can be roughly split into knowledge process-capabilities, facilitating knowledge sharing and dynamic-capabilities, facilitating knowledge transformation ${ }^{1}$. In Trunfios \& Campanas (2019) integrative model, this kind of Human Capital needs to be understood as highly interlinked with Social Capital and ICT, the two master

Figure 1: Drivers for innovation within the knowledge-creating destination; adapted from Trunfio \& Campana (2019), Ozseker (2018) and Roberts et al. (2012); red marks indicate analytical focus of this study

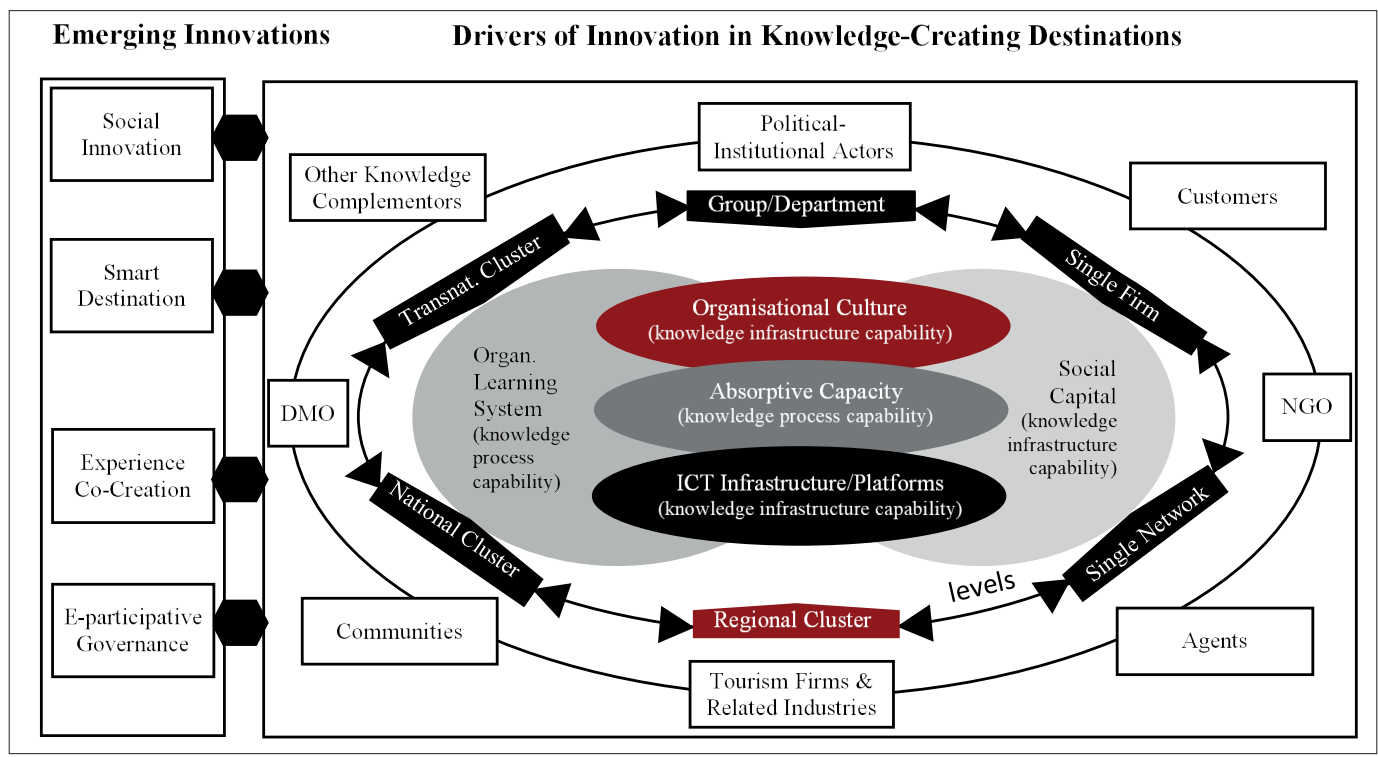


enabling-platforms or knowledge infrastructural-capabilities. Due to the high complexity of knowledge as a socially constructed phenomenon bound to individuals (Schuhbert, 2018), organizational culture also plays a major role here as an operator for a contingent evolution of the organizational knowledgebase and a primary medium for the social construction of innovative-knowledge. As knowledge absorption implies a merging and transformation of CMM (see 2.2.), culture in its primary function as an "operating system" that watches over the consistency of knowledge structures (path-dependence) ultimately determines the framework of socially viable OL-processes. In other words: culture directs the process of selective linking of new knowledge resources with existing ones. As Schuhbert (2021) notices, the modelling approaches of Roberts et al. (2012), Ozseker (2018) and Trunfio \& Campana (2019) consequently only model parts of a destinations' complex knowledge-creating system. As fig. 1 shows, these complementary parts can be effectively integrated into one another by appreciating their common reference to culture as a central infrastructure and operator for the knowledge-creation process:

Ultimately, the dynamic-capabilities fertilize new solutions to existing problems on the basis of converted mental models and at the same time stimulate the evolution of the other capabilities in the set (Thomas \& Wood, 2015; Fischer, 2009). Converted knowledge, be it at the product-level or the process-level provides "innovative knowledge" (Ozseker, 2018), which can be governed into inventions with different degrees of (incremental to radical) disruption in existing production-, process-, organizational-, management or even societal patterns (Trunfio \& Campana, 2019). The change of existing societal patterns refers to social innovations, a conceptual approach to describe the "product and the process of collaborative innovation in order to develop creative and imaginative communities [...] Social innovation thus draws on social capital of networks in order to encourage the imagination of new opportunities and alternatives" (Mosedale \& Voll, 2017,p.2). Through its emphasis on social interaction as both a source and purpose of innovation, the social innovation category thus possibly matches best the idea of tourism as a catalyzer for sustainable regional development, especially at the community-level (Mosedale \& Voll, 2017).

\subsection{The Role of Culture in the Formation of Mental Models}

The idea of an organizational "knowledgebase" as a collective memory storage of an organizations' mental models (Nonaka \& Takeuchi, 1995) proves to be helpful if we conceive innovation as a dynamic plug-and play process of integration and (re-)combination of variable internal and external knowledge resources that can be sourced by local core-stakeholders through a variety of exchange-channels with a multitude of complementary partners on different geographical scales (Binder, 2017). Knowledge can be simplistically conceived as the result of collectively (emotionally positive) reception of successfully applied problem-solving strategies. These are grounded in a specific understanding of cause-and-effect-relationships (or theories, see below) that convey meaning and action-orientation to organization members (Schmidt, 2005; Probst et al., 1999). The genesis of knowledge is bound to an evolutionary continuum of conscious and sub-conscious data-processing and -contextualization, as fig. 2. demonstrates:

Figure 2: Evolution of knowledge into various state forms; based on Nonaka \& Takeuchi (1995), Probst et al. (2002), Hjalager (2010), Gretzel et al. (2015) and Ozseker (2018)

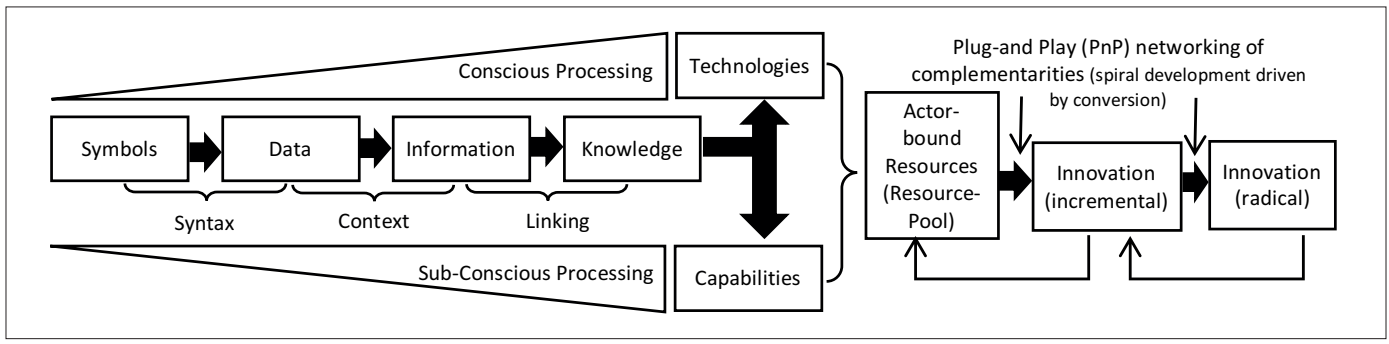

As figure 3 highlights, contextualized and selectively linked data shape the network-like form of mental models in the cognitive autonomous apparatus of the individual human mind (Rook, 2013). The influential approach provided by Argyris et al. (1985, p.82) here distinguishes "Espoused theories [which] are those that an individual claims to follow [and] Theories-in-use [which] are those that can be inferred from action". The theories-in-use (TIU) thus refer to implicit or latent mental models about system-environment relations and causalities, while espoused theories-of-action (ETA) describe 
their conscious or manifest, socially accepted/compatible counterparts (fig.3). The TIU thus share characteristics with capabilities and the ETA with technologies. Together, they form the substance of organizational knowledge-bases that consolidate a destinations' immaterial resource-pool (Raich, 2006).

\section{Figure 3: Evolution and types of mental models; based on Schmidt (2005) and Argyris \& Schön (1983)}

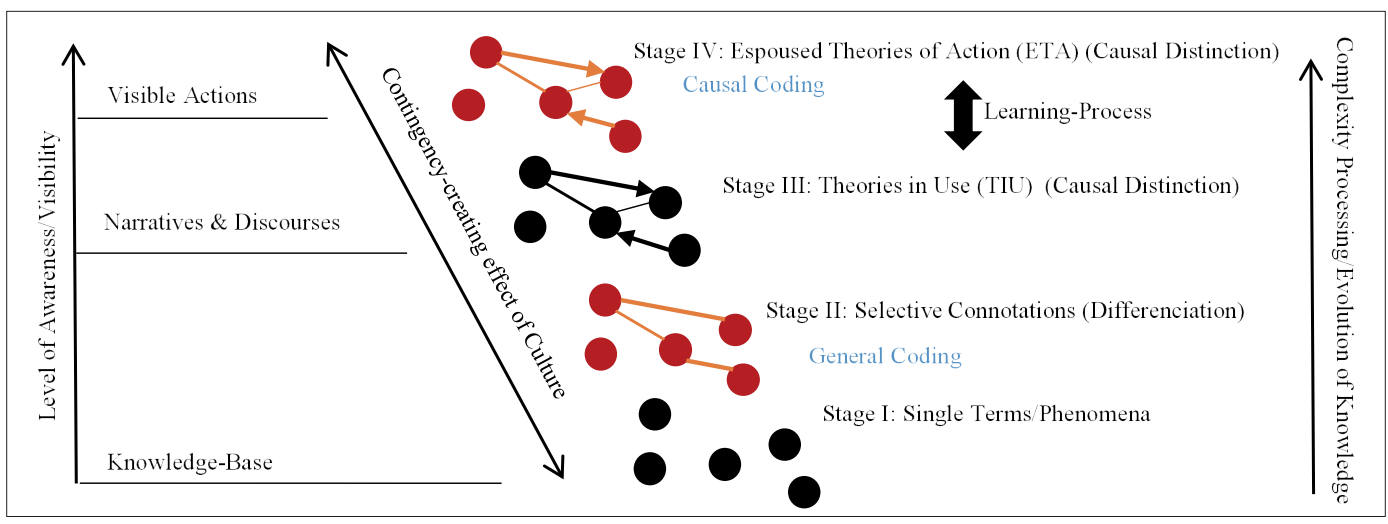

Absorption and conversion of knowledge from the pool can also be described as a process of merging and transforming of these mental models. Culture plays a pivotal role here as "an acquired system of knowledge for interpreting experiences and generating actions [...] a network of values, beliefs, cognitive and normative orientation patterns that holds the system together on a spiritual level" (translated from Klimecki \& Probst, 1990, p.42). In a circular-causal process at the interface between action, observation, communication and experience, culture selectively and contingently aligns perception and interpretation patterns of individual organization members with existing mental models in the knowledgebase and is in turn aligned by them (fig. 3). The result is a self-referential, circular-causal structure of progressive contingency processing, which lays the foundation for the path-dependence of system-specific thinking, feeling and acting (Schuhbert, 2018). This interdependence qualifies knowledgebase and culture as highly intertwined or even synonymous concepts (Nonaka \& Takeuchi, 1995; Schmidt, 2005). As a result of these specific path-dependencies of social knowledge construction, new knowledge can only be absorbed by a socio-economic system if there is a sufficient degree of overlap with the already existing organizational knowledge (Cohen \& Levinthal, 1990) or to put it other words: if there is an overlap in the "knowledgebases" (Nonaka \& Takeuchi, 1995) of interacting socio-economic systems or organizations. Adopting new knowledge from external sources can only succeed comprehensively if there is sufficient cultural similarity between the sender and recipient organizations (see for example the case studies by Pechlaner et al., 2014; Döpfer et al., 2016; Kofler et al., 2018). Otherwise, the absorption is hindered by the persistence-tendencies of the contingency-processing system and destinations' benefit from the diversity of mental models within the resource-pool can can be inhibited. The same applies to the dynamic does the dynamic Plug and Play activation of parallel, multispatial, hybrid network-structures and the evolution of complementary innovative knowledge (fig.2).

Consequently, it is reasonable to assume that a common culture "imprints" the mental models of the various actors in the destination ecosystem Schuhbert (2013). To boost innovativeness, this must happen in a way that sufficient compatibility is guaranteed and simultaneously the variety of mental models is maintained and balanced. Culture can then serve as a proper relational transition-medium for successful knowledge-spillovers. The same applies to conversion, as discrepancies between absorbed latent TIU and manifest ETA can trigger failures in established target-means schematics, while the uncovering of these discrepancies (analogous to conversion) can induce disruptive or radical organizational learning (Rook, 2013; Binder, 2017; Pechlaner et al., 2014) that in turn favorites respective innovations (fig.3). In this context, conversion also offers the possibility for the destination core actors to recognize in how far their development (here: towards sustainable tourism) is hindered by previously unconscious assumptions.

How should culture ideally be constituted if it is to optimally increase the innovative-capacity of its actors? Empirical research on this subject is scarce in tourism so far and especially for the DC. However, 
few approaches have gained growing attention and application in the analytical practice over the past 30 years (Schuhbert et al., 2020). One influential approach has been presented by the 2004 study of the "Global Leadership and Organizational Behaviour Effectiveness Research Program" (GLOBE), which classifies national and organizational culture for 59 participating countries via a set of 9 analytical dimensions (House et al., 2004) (fig.5 and Appendix fig.10). The model integrates and expands previous approaches such as the acclaimed model by Hofstede (2001) or the model by Kluckhohn \& Strodtbeck (1961). Analytical evidence (Zhao et al, 2012) suggests favorable conditions for a kickstart of the innovation-system in those DC whose cultures show a disposition to higher Power Distances, In-Group Collectivism and Humane Orientation. Future-Orientation together with a balancing of In-Group Collectivism in favour of Institutional Collectivism however gain more and more as the innovation-system evolves (as it is the case in many Industrialized Countries; see Schuhbert et al., 2020).

\subsection{Cultural Engineering as an element of Destination Governance?}

The channeling of innovative knowledge into social or sustainable innovations not the least requires strong leadership, which opens up the question of governance. Governance theories in tourism, in particular the actor-centered ones see Raich (2006), emphasize the idea of subsidiarity - a counter-flow of bottom-up and top-down impulses to enable community-influence in destination development (Pechlaner et al, 2020; Kagermeier, Lahoucine \& Elfasskaoui, 2020).

While public institutions can use knowledge and information as soft measures besides hard and power-based measures to top-down stimulate an actors' behavior conducive to innovation (e.g. formation of collaborative networks for a collective sourcing of knowledge from the resource-pool, administration of ICT-platforms etc.), bottom-up participation highly depends on successful self-organization of the core-actors (Raich, 2006; Schuhbert, 2021b). This takes place primarily through the formation of communities which are therefore often decisive for the governance of a destination and its' innovative capacity (see Pechlaner et al., 2012; Pechlaner et al., 2014; Volgger \& Pechlaner, 2017).

As micro-clusters of interdependent, occasionally cross-sectoral core-actors, communities emerge emerge through an accumulation of Social Capital in a given segment of the destinations' ecosystem (Nunkoo, 2017). From a structural perspective, the Capital often manifests organically in localized informal, generally sketchy, but occasionally strong exchange-relations, which can serve as knowledge pipelines among community members (Fuchs \& Baggio, 2017, Ozseker, 2018). These favor in particular the sharing of tacit knowledge (Structural Social Capital) powered by considerable levels of trust and common goals (see Pechlaner \& Bachinger, 2010; Döpfer et al., 2016; Kofler et al., 2018) or by compatible action-orientations (Relational Social Capital). The latter already implies that organizational culture(s) play a key role here. As previously said, these orientations build upon culturally-shaped mental models that strive to sustain themselves and ultimately shape the processing of new external knowledge. CMM thus serve as an operating system for the knowledge pipelines (Schuhbert, 2021b). The resulting path-dependencies embedded in this operating system impose a kind of cultural coherence or similarity between sender and recipient and thus determine the success of external knowledge-absorption between both sides (Schuhbert, 2021a). Consequently, knowledge-based self-organization within a community depends on the basic compatibility of CMM among the knowledgebases of senders and receivers (Cognitive Social Capital). Cultural compatibility is consequently a major prerequisite for community formation.

Studies indicate that the mostly SME-dominated tourism industries in IC and DC are however often culturally characterized by a lack of outward strategic and entrepreneurial orientation (Schuhbert, 2018). Furthermore, low-power communities tend to be marginalized (Nunkoo, 2017). This (cultural) disposition can have a negative effect on their absorptive capacities, especially when it comes to the adoption of "highly technical formal knowledge" (Thomas \& Wood, 2015, Mirtsch et al., 2020; Schuhbert, 2013). Consequently, this lock-in limits the tourism sector's proactiveness, cooperativeness, and risk-propensity and the activation/intensification of cross-sectoral linkages with a detrimental effect on innovativeness (Lejarraja \& Walkenhorst, 2007; Pechlaner et al., 2012; Pechlaner et al, 2020; Schuhbert, 2021). The effect of direct, top-down interventions to systematically change the organizational culture(s) towards a more favorable configuration (see 2.2.) is controversially discussed in the literature and reaches from a positivistic position assuming a changeability through managerial guidance to a complete neglection of changeability due to the emergent nature of organizational culture (Schmidt, 2005; Raich, 2006). Last but not least, the general lack of scientific evidence on the dynamics of governance patterns in regional network-systems (Pechlaner et al , 2014) renders a targeted intervention into the culture-based determinants of the 
fragile interplay of top-down and bottom-up processes a riskful undertaking - even for the dedicated purpose of increasing its ability to innovate (innovation governance).

\section{Methodology}

\subsection{Research Areas}

Both research areas, the Guba-Xachmaz Economic Region in Azerbaijan ("Guba") and the Napo Province of Ecuador ("Napo"), have been previously used as case examples for a comparative analysis of their respective resource-pools (Schuhbert, 2018). A comparison makes sense since Azerbaijan and Ecuador show both similarities and differences in a series of important parameters related to innovation and sustainability, whose sociocultural and psychological determinants (CMM-processes) shall be investigated in the course of this study. In this light, fig. 4 illustrates the foremost innovation indicators (top left) and the residual parameters in addition.

Figure 4: Parameters of sample selection based on WEF (2015-2020a\&b)

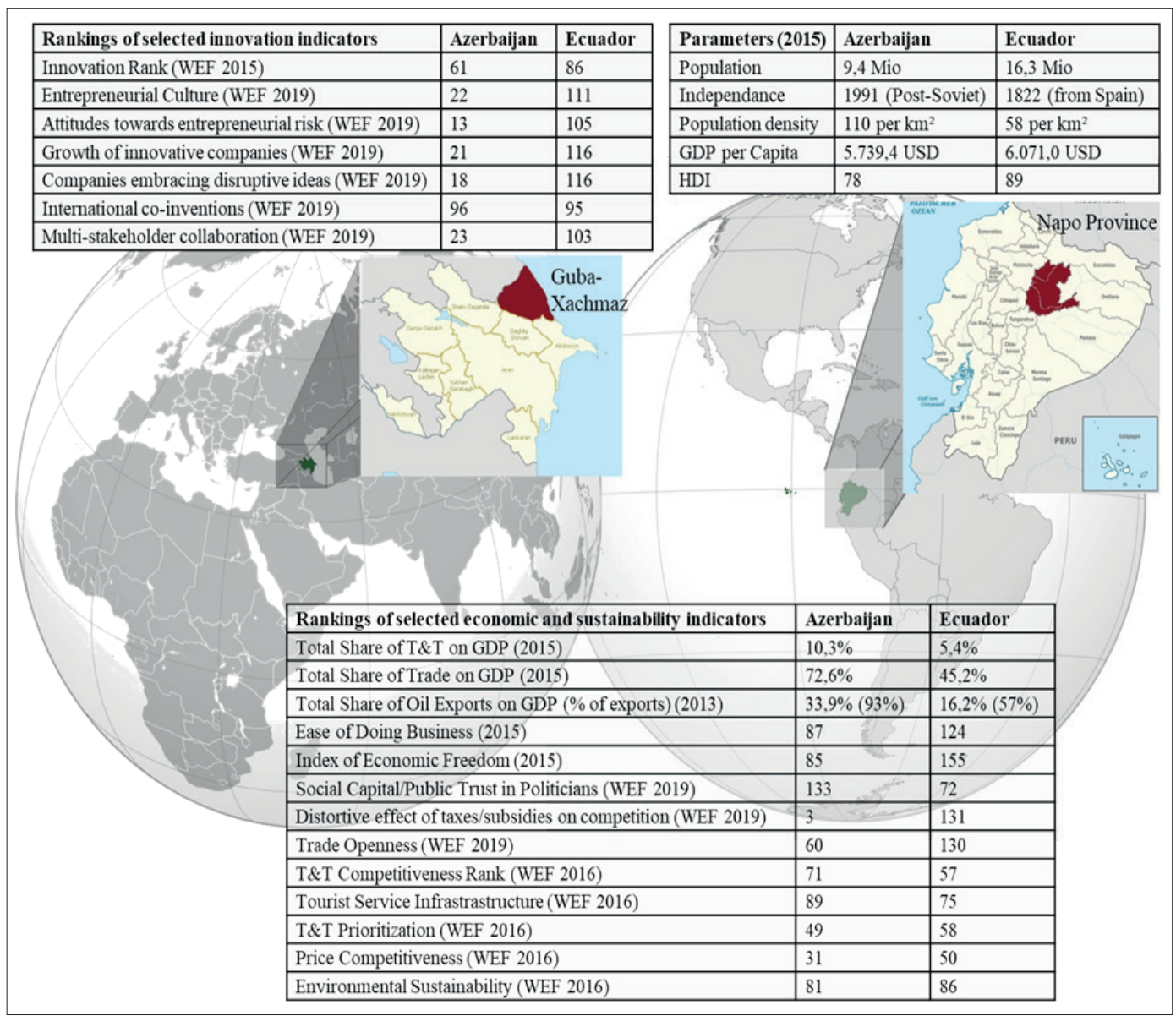

The Worldbank has classified Azerbaijan and Ecuador as Upper Middle Income Countries (UMIC). Within the UMIC, Azerbaijan and Ecuador share many similarities regarding size, population (density) and economic structure - the latter in particular concerning the substantial importance of the oil extraction-sector. Taking the year of 2015 as a statistical reference, both countries have been very close to one another regarding indicators, such as infrastructure, market-size, price-competitiveness or environmental sustainability. The 
same applies to their ranking in the Economic Complexity Index (Ecuador: Rank 113; Azerbaijan: Rank 114), which measures diversity and extent of the accummulated knowledgebase of a society based on the scope of economic activities (Hidalgo \& Hausmann, 2009). Growing differences are observable in macroeconomic environment, education, goods- and labour market-efficiency, ICT, security, institutions and especially in aspects of primary relevance for this study such as business sophistication and innovation, where Azerbaijan is generally better suited than Ecuador. Consequently, Azerbaijan held a better rank for global competitiveness of its economy in 2015, but Ecuador, due to its better tourist infrastructure and higher quality/quantity of natural resources, held a better rank in Travel \& Tourism competitiveness.

Both countries temporarily displayed enormous GDP growth in the first decade of the 21st century (especially Azerbaijan), which began to level off sharply in the second decade under the impression of falling oil prices and hesitant reforms. While Azerbaijan was temporarily able to secure the financing of its medium-term development plans, the side effect of extractive economies (dutch disease) became apparent in Ecuador in increasing national debt and sharply increasing poverty rate, which i.a. was associated with an increased tax burden on the predominantly SME-based private-sector. Necessary reforms in legal security, privatization and reforms in the finance- and energy sectors remain incomplete to date. In terms of economic policy, both countries pursue increasing market- and trade-liberalization (Schuhbert, 2018).

As a result of several successive privatization programs, Azerbaijan was able to significantly improve its framework conditions for private entrepreneurship in contrast to Ecuador (Karimov, 2015). However, this must not hide the fact that both private sectors are highly dependent on state and administrative structures (Central Intelligence Agency, 2021a \& b).

The political culture of both countries is characterized by historical breaklines that run along ethnic, religious, ideological, socio-economic and also geographical boundaries. Neopatrimonial structures among Azerbaijani ethnicities (e.g. the Lezgins in Guba) and the older generation build upon a broad, culturally-based acceptance (Friedrich \& Diamond, 1994), which supports the current semi-democratic "authoritarian regime" (EIU, 2019) that rules the country since 1993. The political landscape of Ecuador, on the other hand, is characterized by a lively, unstable and conflict-laden, public discussion-culture in which ethnically charged tensions arise between members of indigenous Quechua communities and the Colonos, the descendants of the Spanish settlers. In contrast to Azerbaijan, however, Ecuador's "flawed democracy" (EIU, 2019) also allows successful political participation through bottom-up initiatives of various (in some cases well-organized) interest groups, associations and communities. In the past few decades, indigenous associations in particular have thus (partially violently) opposed further market and trade liberalization in favor of a more sustainable development. Nevertheless, massive environmental damage from oil production can be seen in both countries, for which politicians have not yet found a consistent answer. Despite the designation of protected areas, environmental degradation continues to take place on an incredible scale and, especially in Ecuador, local communities are increasingly being put on the defensive as a result (Munoz Barriga, 2014).

These similarities and differences qualify the two countries as promising cases for a comparative analysis to tap into the complexity and highlight the peculiarities of sustainable tourism development within the UMIC group. This is especially true since both destinations (prior to the start of the COVID pandemic) were in the growth phase of their product life-cycles, as the steep rise in international tourist arrivals between 2011 and 2017 suggests (Azerbaijan:+57,1\%; Ecuador:+58,3\%).

On a regional level, Guba and Napo have been selected as cases. As Schuhbert (2018) states, both regions are amongst the least densely populated and least economically diversified of their respective countries and characterized by strong regional ethnicities: the Quechua in Napo and the Lezgins in Guba. Despite different degrees of administrative autonomy, they share a similar economic structure based on small enterprises active in agrarian production, wholesale and retail with a low share of manufacturing. Nature-based tourism, such as adventure-, eco- or community-based tourism, is the leading tourism segment in both regions due to the presence of the Shahdaq National Park in Guba and the Sumaco Biosphere Reserve in Napo. Both regions belong to the most popular domestic nature tourist destinations and both have profited from their countries' steep increase in international tourist arrivals (Schuhbert et al, 2020 and Schuhbert, 2018). However, international demand has most probably a higher share of tourist demand in Napo than in Guba. Consequently, the hospitality sector in Napo has a much larger share of the economy (16\% vs. $9 \%$ ), surpasses the number of establishments by a factor of 3 and has a higher degree of diversification than Guba. Company-spaning value chains and thus complex cross-sectoral products are scarce in both regions. Despite the considerably lower competitive pressure, the accommodation business in Guba produces a substantially higher output on innovations than in Napo. Here, the frequency of 
inventions roughly amounts to one novelty on average per year. Analogous to the Western European accommodation business (Hjalager, 2010), the absolute majority of the Napo and Guba inventions represent incremental improvements to existing processes in the fields of marketing and product design with few novelties touching the field of social innovation (Schuhbert, 2018).

\subsection{Case-study design}

\subsubsection{Design and sampling}

In the context of the conceptual framework specified in fig.1, it is helpful to direct the analytical focus of this study on the CMM of core-actors in both destinations to highlight sociocultural and psychological factors affecting sustainable tourism development. An analysis of the CMM can provide a promising methodological approach here as their path-dependent filter-effect on new knowledge can be a major inhibitor for social innovation (Schuhbert, 2018). As fig. 3 shows, TIU and ETA are analytically accessible through their effect on the construction of narratives. On this basis, narratives represent a structure of consistently merged mental models whose contingency is provided by a culture which "imprints" the models (cultural traces). The TIU are usually more action-guiding and are consequently of analytical relevance, however, they are more difficult to extract from narratives due to their implicit nature and cause-effect structure. With the help of the GABEK method (see 3.2.2.) and a combination of narrative and other low-structurized expert interviews, both explicit and implicit/tacit structures can be visualized in natural language processing (Hollstein, 2019). This suggests a qualitative-narrative approach to the research question. Since the reconstruction of ETA and TIU poses special challenges due to their dynamic nature (communicative reflection during the interviews may induce conversion and change of the models) and their difficult separability, the focus of the analysis will be consequently on the the sub-structures or substrates of TIU and ETA (see stage II in fig. 3)

To isolate the CMM as essential substrates of the preset collective knowledgebase of the Napo and Guba destinations, narrative guideline-interviews were conducted with selected core-actors from the fields of accommodation, gastronomy, tour operation, culture, education, conservation, communities, agriculture, transportation and tourism governance (Munoz-Barriga, 2014). The selection was based on a maximum variance sampling method and produced 74 short and extended interviews in the Napo campaigns (2010-2013) and 34 in the Guba-Khachmaz campaigns (2016-2018). Due to the focus on cultural tracers (which use to change very slowly over time) mental models can even be extracted from interview materials, that have been collected a few years ago (see also Schmidt, 2005; Kutschker \& Schmid, 2008).

The guideline concepts share a common set of core questions - expanded for additional questions in the Azerbaijani case. The interviews themselves were designed for a one-hour conversation and buildt to a large extent on semi-structured, open questions as conversation-stimuli to get started with narration and tap into latent structures (see above). Figure 9 (Appendix) documents the assignment of the question-complexes to the conceptual framework.

\subsubsection{Evaluation methodology}

Before the background of the above research question, the direction of the analysis can be twofold (Mayring, 2008):

1) with an analytical perspective on the manifest interview content (object-level) and

2) with a meta-perspective on the structural characteristics of the models (structurally -functional perspective) which can be helpful to delve a bit deeper into the latent dimensions of the mental models

The conceptual framework and the adaption of the GLOBE dimensions (Zhao et al., 2012 and fig.10) provide a blueprint to analyse the reality of actors' understanding of Sustainable Tourism in both destinations at the substrate-level of ETA and TIU. The reconstruction of the substrate is realized by making use of the GABEK methodology. GABEK ${ }^{\circledR}$ (German abbreviation for holistic mastering of complexity) visualizes connotated terms in complex linguistic networks, assisted by the Software WinRelan $\mathbb{C}$ and its computerized steps (Pechlaner \& Volgger, 2012). Through a quantification of connotated terms, even the latent structures of mental models can be made transparent (see also Döpfer et al., 2016). GABEK has a wide field of application in and outside tourism and is thus an accepted research method, which has been tested since 1992 in more than a hundred projects (Schuhbert et al., 2020). For this comparative study, 1.592 text units, 1.200 keywords and about 135.000 connotations have been processed in Napo versus 1.427 text units, 1.935 keywords and 286.000 connotations in Guba - based on about 600 pages of transcript. 
Against this background, a combination of a deductive and explorative approach to data analysis is helpful. As the focus of the study is on the formative power of culture(s) on mental models, theoretically derived keywords (fig.5) shall serve as nodal terms for a GABEK-based explorative reconstruction of the CMM:

Figure 5: Theoretical deviation of nodal terms for the core-web of connotations

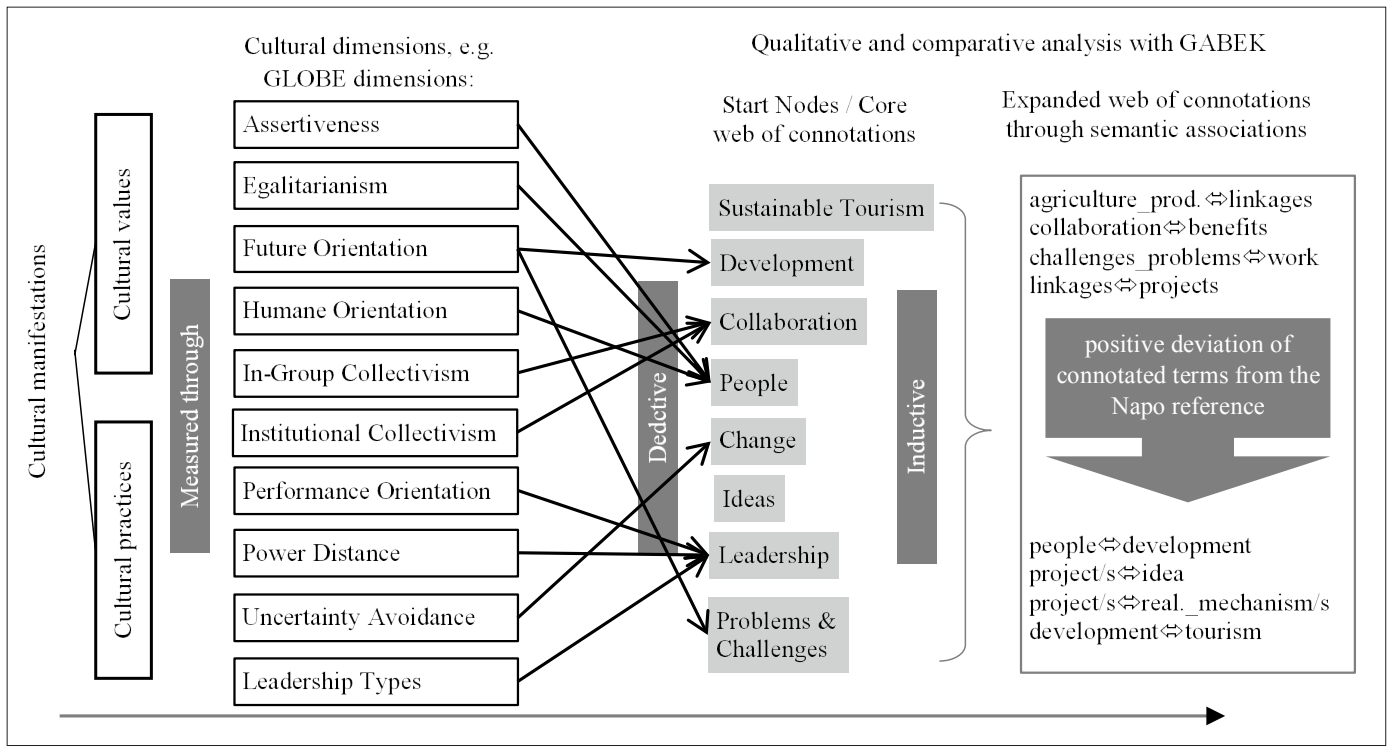

The above seven nodal terms (adopted from Schmidt, 2005 on a basis of Kluckhohn \& Strodtbeck, 1961) serve as the core elements in a terminological web of connotations around the key term sustainable tourism (tab.1). In order to further break down and visualize the differences in the semantic associations of the mental models (see also fig. 3 stage II), the above core-web was complemented by an expanded web of connotations. Key elements or terms of this expanded web were selected from the above-mentioned lists of keywords by using the GABEK-specific method for quantification of associations. Thus, only those terms were included in the expanded web, which showed a minimum of 3 or 4 common citations with one or with multiple of the seven above-mentioned nodal terms. As a result, an adjusted keyword list of 94 terms was created as a repository for the expanded web of connotations. As the adjusted keyword list had to be synchronized with both the Guba and the Napo example to enable a comparative analysis, the resulting 846 connotations show variable levels of relational strength from case to case. This variance in strength allows a much deeper analysis of differences and commonalities in both destinations' mental models through a calculation of positive and negative divergences of the Guba case from the Napo case (serving as the reference). As a result, a spectrum of highly positive and negative deviations can be shown for the same pair of terminological connotations in both destinations.

\section{Interview Results}

Looking at the links between the central term of sustainable tourism and the seven other nodal terms as specified above, it becomes clear that the core-web of connotations is not very densely knit in both the destinations of Guba and Napo. The sociometric analysis in tab.1 gives an overview of the existing connections in this regard. Sustainable Tourism (ST) is thus only very weakly associated with change, collaboration, people and ideas, while the association of ST as a challenge is far more advanced in Napo and ST as a factor of development is more strongly accentuated in Guba. To a certain extent, this may be explained by the different levels of destination development in both case regions, with Napo having already reached some state of disillusionment over the potential of tourism as a medium for sustainable regional development. 
Tabela 1: Quantitative interconnections of nodal terms in the core-web

\begin{tabular}{|c|c|c|c|c|c|c|c|c|c|}
\hline & $\begin{array}{c}\text { ST } \\
(63)\end{array}$ & $\begin{array}{c}\text { Development } \\
(59)\end{array}$ & $\begin{array}{c}\text { Collaboration } \\
(\mathbf{8 3})\end{array}$ & $\begin{array}{c}\text { People } \\
(67)\end{array}$ & $\begin{array}{c}\text { Change } \\
(27) \\
\end{array}$ & $\begin{array}{c}\text { Ideas } \\
(7)\end{array}$ & $\begin{array}{c}\text { Leadership } \\
\text { (14) }\end{array}$ & $\begin{array}{c}\text { Challenges } \\
(129)\end{array}$ & $\sum$ Guba \\
\hline ST (32) & & 2 & 5 & 2 & 1 & 0 & 3 & 10 & n.a. \\
\hline Development (164) & 11 & & 3 & 3 & 4 & 1 & 0 & 4 & 11 \\
\hline Collaboration (66) & 2 & 11 & & 2 & 2 & 2 & 2 & 6 & 13 \\
\hline People (109) & 3 & 18 & 3 & & 2 & 0 & 1 & 12 & 24 \\
\hline Change (41) & 1 & 0 & 3 & 0 & & 0 & 0 & 7 & 4 \\
\hline Ideas (82) & 0 & 8 & 3 & 4 & 2 & & 0 & 0 & 17 \\
\hline Leadership (7) & 1 & 0 & 0 & 0 & 0 & 0 & & 3 & 1 \\
\hline Challenges (122) & 3 & 8 & 3 & 7 & 6 & 3 & 0 & & 30 \\
\hline$\sum$ Napo & n.a. & 2 & 8 & 7 & 9 & 3 & 6 & 42 & \\
\hline
\end{tabular}

The remaining links in the nodal terms' web of connotations show a different pattern of distribution in Napo and Guba, where the imbalance of the sample is probably a factor that has to be taken into account. Be it in an original or a corrected for sample-size form, Guba always shows stronger associations between development and challenges, collaboration, people and ideas than in Napo, while the latter more strongly associates development with change and people with challenges. This points to fundamental differences in the formation of mental models in the field of ST that may be explained by different cultural dispositions. However, as tab. 1 shows, only about 17,7\% (77 of 435) of all connotations in Napos and 16,2\% (100 of 616) in Gubas core-web can be represented by restricting the analysis to the interconnections of the nodal terms alone. Building upon it, a Nearest-Neighbour-Clustering of the terms from the adjusted keyword-list was applied for a graphical analysis of the CMM (fig.6 and 7).

\section{Figure 6: CMM of Destination Napo with spectrum of highest negative deviation of Guba towards Napo}

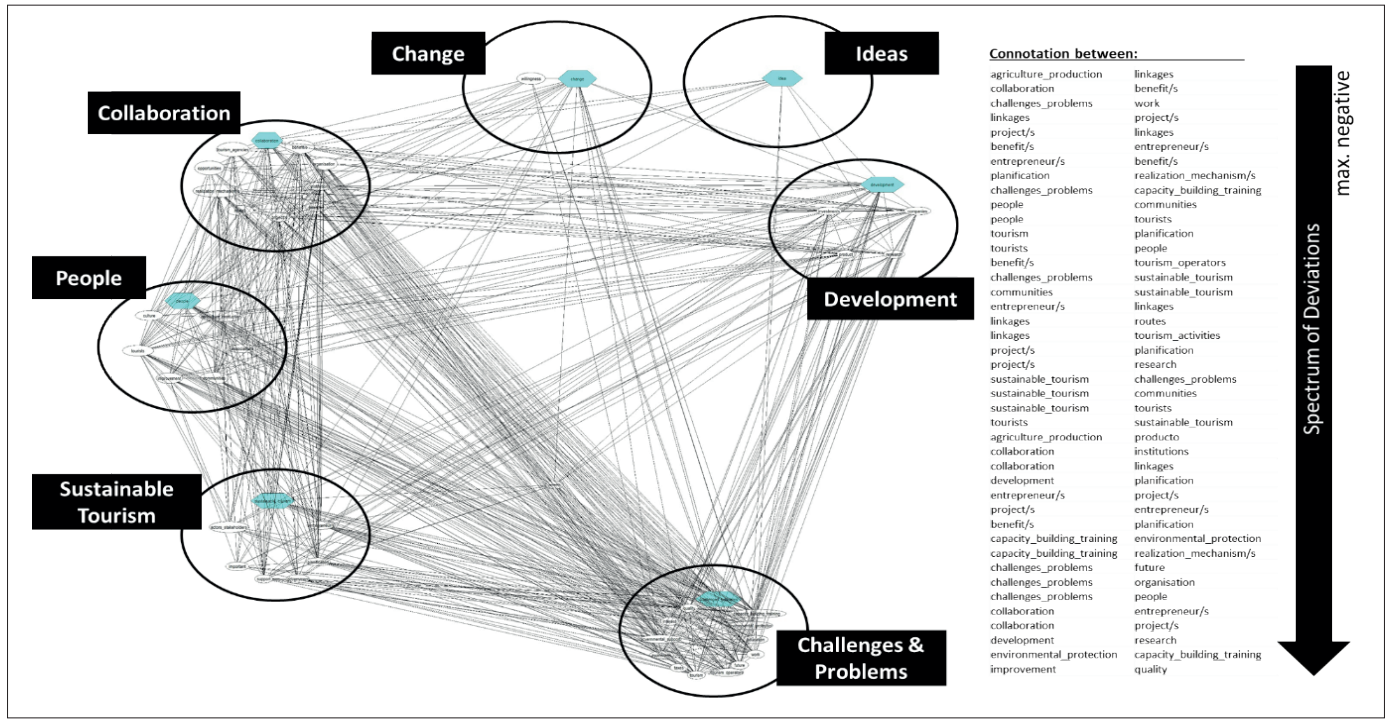

Further analytical insight can be produced here through the spectrum of deviations described in section 3.2.2. This can be helpful to differentiate highly positive and negative quantitative deviations by the sum of connotations between the Guba and Napo case and consequently to highlight the differences and commonalities of both destinations' CMM to explain the observed differences in innovativeness (see 3.1). In the following, this shall be done in extracts with selected expanded terms connected to the nodal terms.

\subsection{Sustainable Tourism}

Both destinations generally share the view that the government must bring the actors closer together so that the tourism sector can operate responsibly in the interests of sustainable tourism. This concerns in 
particular the setting and control of standards in the area of service-quality and ST as well as the expansion of basic services and educational support for entrepreneurs and the population. In Guba, the main challenge is seen in a lack of understanding or awareness on tourism among entrepreneurs and a lack of complexity in process-thinking, while in Napo a lack of trust becomes apparent in the relationships of the public and private sectors and a decline of Social Capital which could not even been repaired by the destinations' multi-stakeholder forums (mesa de turismo). This could be an explanation why national and foreign tour operators play a pivotal role as mediators, developers and coordinators in both cases, where critical voices towards the government are generally scarce from Guba representatives. This also concerns the impact of tourism on environmental degradation, which is seen more clearly and increasingly as a threat for ST in Napo than in Guba.

\section{Figure 7: CMM of Destination Guba with spectrum of highest positive deviation of Guba towards Nap}

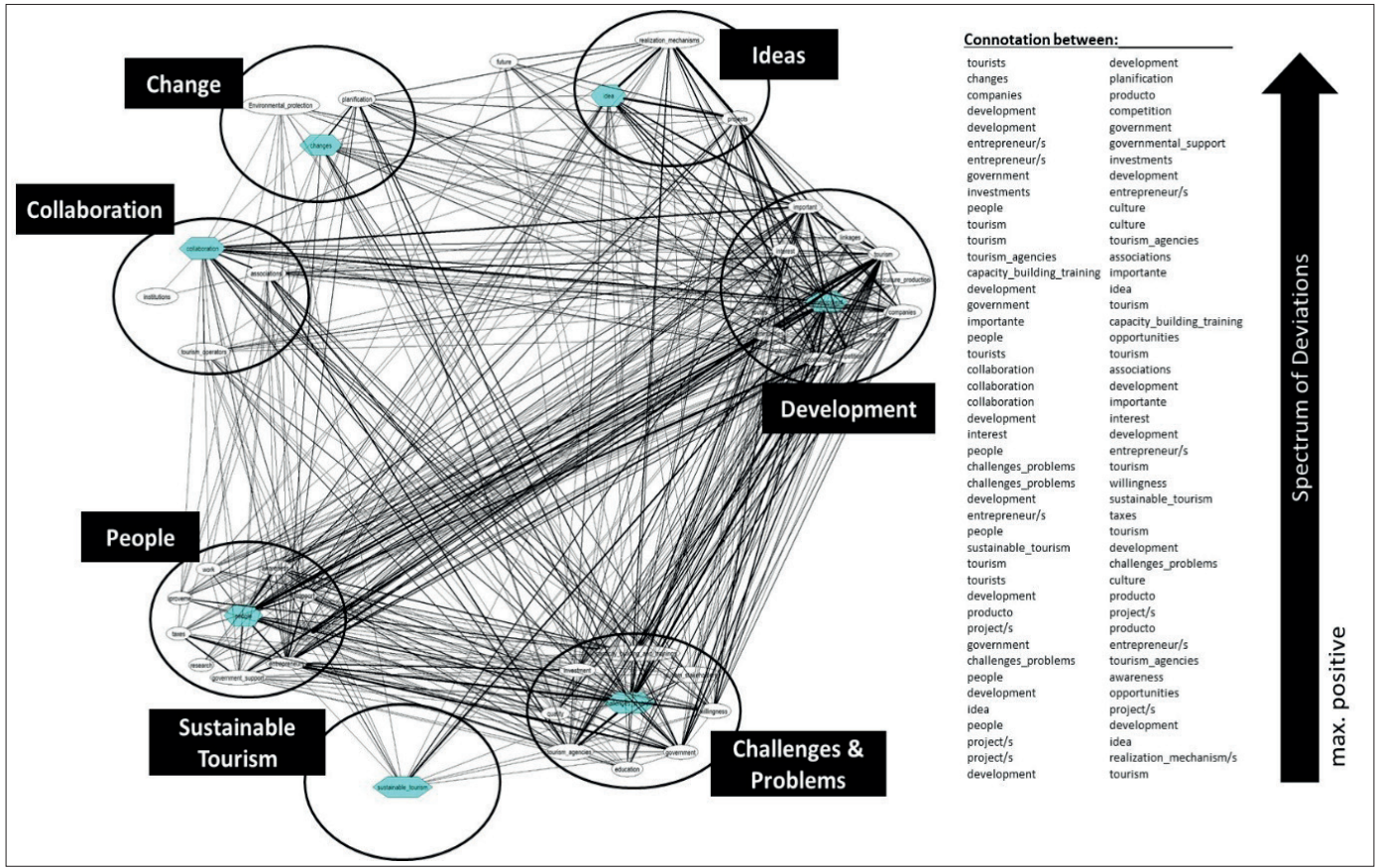

The association of sustainable tourism with communities is particularly different in both destinations, as the spectrum uncovers a much stronger relevance in Napo. The role of communal infrastructural development is consequently seen much more critical in Napo than in Guba following ongoing infrastructure expansion on the part of the oil industry. Napos difficulties furthermore contrast Gubas positive outlooks on tourism as a means to boost agricultural production and community development and community development - especially when it comes to Napos mixed experiences with linking tourism to its extensive Cacao production. On top of that comes the failure of many CBT-projects due to internal conflicts over the distribution of tourism revenues, political protagonism, lack of entrepreneurship and marketing.

\subsection{Development}

When it comes to the concept of development, its notion as a challenge becomes apparent in the positive spectral deviation of Guba over Napo. The same goes for a multitude of other nodal and expanded terms such as people, ideas, products, government, competition and support. In both destinations, a strong growth in tourism demand and supply is seen to have taken place over the past few years, boosting the need for public services and infrastructure. While the negative side effects are more and more broadly perceived and discussed in Napo, Azerbaijani interview partners primarily emphasize its positive effects on the expansion of trade, procurement of resources, evolution of complex products and positive learning curves which are about 
to propel a positive regional development spiral. Improvements in coordination and organization are described as major prerequisites for regional development both in Guba and Napo. The concept of a regional DMO finds some appreciation here but the lack of cooperativeness among entrepreneurs and the lack of professional personnel to run a DMO are considered major obstacles for destination development on the long term.

While Guba, possibly driven by a more positivistic view on international trade (section 5), more generally focusses the possibility here to absorb knowledge and standards via flexible exchange-relations and creation of mutual synergies, the activation of Human Capital (people) in Napo is bound to the empowerment of local communities (most of them indigenous communities). Due to the problems in CBT development and the lack of Social Capital, related projects failed to unleash the creative potential, especially of the indigenous communities. A major problem in both destinations is thus the lack of awareness on the potentials of sustainable tourism for local development - especially in agrotourism.

Although innovative entrepreneurship emerges only sporadically in both destinations, Napo and Guba have high hopes for the young generation. In particular, Azerbaijan relies on the absorption of knowledge and ideas from returning Azeri experts and (their) international networks. Demonstration effects serve here as a major mechanism for absorption in both countries as the possibility of taking over successful concepts is especially in Azerbaijan expected to spirally drag more and more local partners and their creative potentials into development projects.

Even though direct criticism of public actors (probably as an effect of the different political systems) is a bit restrained in Azerbaijan compared to Ecuador, there are fundamental differences in orientation on socio-economic policies. This becomes particularly apparent in the notion of competition. In Napo, high seasonality combined with market concentration and very low-average occupation-rates in the accommodation industry triggered demands for active public intervention into pricing-mechanisms (tab.1). On the other hand, the role of the state in Guba is primarily seen as a provider for framework conditions, as coordinator and incentivizer with free competition as a healthy motor for the development of products, ideas, and qualities. This suggests a more neoliberal access towards the phenomenon of competition in Azerbaijan than in Ecuador, which can be contextualized with both countries' recent history (see 3.1). As such, the stakeholders' vision for development in Guba is more oriented on big business infrastructural projects (such as the recently established Shahdag Resort), while a majority of Napo actors follow a vision of SME-based tourism.

\subsection{Collaboration}

The idea of collaboration appears to be more inspired by trade in Azerbaijan than it is in Ecuador. This is i.a. expressed in the higher quantitative association of the term with long-lasting and fairly distributed benefits. While the interviewees in Guba thus describe a slowly growing cooperativeness in the private sector, which is directed to flexible and temporary alliances with national and international partners, actors in Napo focus much more the local community perspective and the negative effect protagonism of national public and private stakeholders (e.g. TOs, community leaders) has on their capacity for self-organization. Consequently, Napo shows stronger connotations between collaboration and linkages, institutions, entrepreneurs and projects than Guba. Both destinations generally concur in their appreciation of the central role that institutional associations are about to play in sustainable regional tourism development - especially in their proposed role as trust-builders and mediators that are to ease the trust-gap and integrate and coordinate the business models of varying partners into tourism routes of different geographical scales.

While the stakeholders in Napo can already rely on experiences with cross-sectoral value chains (mostly from the field of agrotourism) and their linkage with proposed thematic routes, the potential of cross-sectoral linkages is more broadly conceived in Azerbaijan. This is to some extent explainable through different endowment with natural and cultural attractions and traditional production types (e.g. Silk-Road and silk production in Azerbaijan; see Schuhbert et al., 2020). Even though professional tourism started in Napo already in the 1970s and thus 20 years before Guba, only very limited linkage-creation with agribusiness has been achieved in the destination. Approaches by various public institutions to transfer the cacao's partially high development dynamics to the tourism industry have been less successful due to a lack of willingness to establish stable, strategic cross-sectoral linkages on both sides. Even though some sustainable flagship-projects demonstrate a proposition for systemic thinking in circuits and linkages existing in Napo, experts see the need to further invest in awareness by making investments into projects and organizational capacities of the communities to boost linkage-formation.

\subsection{People}

The recurring focus on the awareness-problem reflects the interviewees' notion on people. The term is more strongly associated in Guba with awareness, entrepreneurs, opportunities, culture and support 
while in Napo stronger connotations are visible with communities, environmental protection and future. This could be another slight indication for the Napo stakeholders' more collectivist attitude over a more competitive attitude on the part of Guba. Both destinations share a high optimism for tourism as a catalyzer for local people's socio-economic development, primarily through jobs and entrepreneurship, and to stop regional migration to the capital areas. In Napo, the partly historically grounded trust and credibility deficits, the tendency to repulse personal responsibility and the blurred perception of potentials are are central problems of motivating people for ST. These factors complicate campaign works of associations in the area of qualification and project organization. The fact that the crude oil found in Napo is of poor quality, however, nourishes the opportunity that in the medium term a new kind of thinking in the direction of alternative sources of income will have beneficial effects. Additionally, the rise of domestic tourism and the resulting exchange of people are supposed to positively affect the attitude towards sustainable behavior. In Azerbaijan, the notion is similar. However, the focus is on knowledge transfer problems, the lack of associations in the regions, and insufficient support between the local population and local authorities or a lack of effective decentralization. The identity-creating effect of tourism on culture is seen in Azerbaijan as a possible motivator for the peoples' change of mind.

\subsection{Change}

Compared to Napo, change is consequently greater associated in Guba with planification, ideas and projects, while in Napo it is stronger linked with entrepreneurs and environmental protection. This suggests that the vision and direction of tourism-driven development is clearer in Napo than in Guba. The idea of change in both destinations is strongly bound to a stepwise, incremental change of behavior provided by demonstration effects and project work (see above). While in Azerbaijan change is strongly provided through innovation and the adaption to market shifts, Ecuador relies more on political intervention, qualification and an "empiric" form of entrepreneurship. Both destinations differ a bit in their valuation of change. In Napo, it is widely seen as a threat by many stakeholders, while Guba has a more positive attitude toward it (e.g. when it comes to the effect of route development on conservation). This, not the least, stems from a stronger belief and practice in planification of individual development (especially at a company level). When it comes to sustainable tourism, some Azerbaijani tourism companies also conceive financing of innovation via credits or the supposed limitations imposed by sustainability-standards as a source of fear.

\subsection{Ideas, Leadership \& Challenges}

While ideas in context with innovation have a substantially higher connotation with development and people in Guba (see above), they practically do not play any role in the structure of the Napo CMM. The same applies to the notion of leadership in Guba. Before the background of few and less successfull public-private partnership initiatives, Napo actors describe a leadership crisis, nourished abovementioned lack of of responsibility, motivation, awareness, strategic planning and empowerment together with a lack of public decision-making.

As a consequence of the above observations, challenges of ST development are more connected in Guba to tourism agencies, willingness of stakeholders, companies, associations and realization mechanisms while in Napo the focus is more on capacity building, environmental protection, organisation, future and political problems. Napo, in particular, has to struggle with future aggravation of population growth, infrastructural and urban expansion, oil and mining extraction, environmental degradation, resource depletion and seasonality of tourist demand. A more effective and responsible multi-stakeholder collaboration and coordination is seen as quintessential here to cope with this challenge (fig.4).

Figure 8 summarizes the findings from this section in detail and with reference to the GLOBE-criteria as a preparation for the following discussion.

\section{Discussion}

The results document the effects of cultural "traces" on the formation of mental models related to sustainable (tourism-)development in Napo and Guba. Despite their different degrees of tourism development, it becomes clear that the concept of sustainable tourism is only marginally interlinked with the collective knowledgebase of actors in both regions.

As already said, culture-based commonalities and differences within the knowledgebases' mental models can be discussed using the interrelatedness of the GLOBE study (Zhao et al, 2012) as an analytical blueprint. Here, fig. 8 gives an overview about the manifest and latent elements ("engrams") of culturally imprinted 
Figure 8: Key engrams and their association with cultural markers

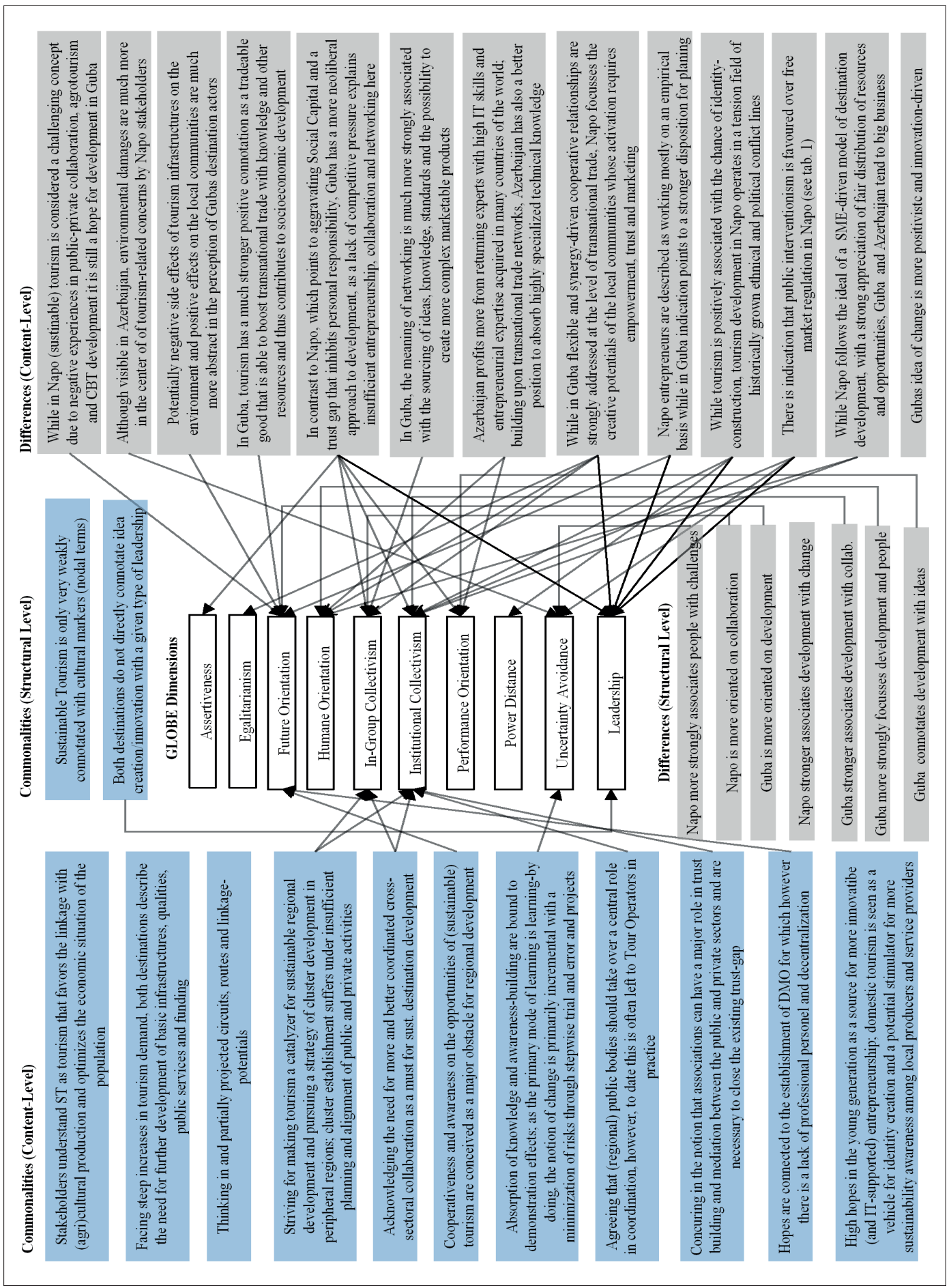


mental models in Napo and Guba. It can be concluded here that many key relationships shown in the literature-analysis between sustainability, innovation and social practices such as future orientation, the balancing of collectivism and uncertainty avoidance are (relatively and absolutely) hardly reflected in the CMM - respectively not anchored in the actors' perception. This mainly concerns the connotation between innovative knowledge, competition and participatory leadership and with collaboration, development and sustainable tourism - although this deficit is much more expressed in Napo than in Guba.

By affiliating the engrams with the nodal terms discussed in section 3.2.2, traces of the cultural imprint can be visualized and explained on a hypothetical basis. This concerns in detail:

- Gubas more positivistic Future Orientation connotated with a higher propensity for planning that could be possibly explained with the countries' historical and contemporary role as a relay between major transnational trade-networks (section 3.1 and fig.4).

- The same role could also explain why collaboration, especially in or between groups of organizations (In-Group Collectivism), seems to have a shorter life than in Napo. They are primarily directed towards fast and flexible access to multiple knowledge-sources, in particular to transnational ones. In the context of its Post-Soviet history, the connotation of tourism-induced identity-construction as a motivator for entrepreneurship and cooperativeness could be considered a cultural marker for Guba as well (for the role of identity construction for entrepreneurship see also Tretter et al., 2014).

- Even though there is a high propensity for building clans and clientele-networks observable in Azerbaijan, which is not necessarily detrimental to innovation in DC as Pinillos and Reyes (2011) show, sustainable tourism-related network relationships would rather be expected in Napo with its focus on communities, higher willingness for open in- and between-group communication and consensus-finding.

- The trust-base between the public sector, private sectors and communities in Napo has been severely disturbed after the failure of various previous multi-stakeholder initiatives, which aggravates coordinated action across institutions (Institutional Collectivism). From a cultural perspective, this could be explained by the historically grounded, perceived marginalization of indigenous communities. Neoliberal economic policies are strongly rejected by them, which opens up an interesting contrast to the Azerbaijani case, where tourism actors pled for tightly limited governmental intervention in regional development processes. Before the background of clientelism and neopatrimonialism in Azerbaijan, this could also be interpreted as a compensation strategy instead of the clear favoritism of neoliberalism. Despite a lack of open criticism, the strong role of tour operators and the observed need for mediating associations suggest a similar lack of Social Capital in Guba as in Napo (which is supported by the findings from fig.4)

- Neopatrimonial structures and the high importance of hierarchies can be observed in both countries, although the Power Distance in Napo is somewhat broken up by local councils' role within the indigenous Quechua communities. The more paternalistic tradition of the regionally dominating Lezgian-culture in Guba on the other hand nurtures the neopatrimonial power-structures observed above (Wilbert, 1994; Friedrich \& Diamond, 1994).

- The wish for Uncertainty Avoidance expresses in both cases in the preference for incremental adoption of innovative knowledge from external sources (see demonstration effects) combined with its test on a trial-and-error or empiric basis. Napos more vital call for public interventionism to avoid uncertainty is a distinguishing cultural element between the Ecuadorian and Azerbaijani case and reflects the more critical attitude of the Napo stakeholders towards neoliberal, competition-based laissez-faire strategies.

- Napos stronger claim for inclusion of communities into decision-making reflects a historically-founded idea of participative Leadership in tourism development in rural-peripheral destinations. At a general level (beyond the actual situation of regional tourism), Azerbaijan is more successful in putting this claim into practice (fig.4)

These findings suggest the Guba and Napo case's comparability in the fields of institutional collectivism, uncertainty avoidance, and power distance. At the same time, there is a higher level of humane orientation to expect in Napo and a higher degree of future orientation in Guba. In combination with with a possibly lower or more balanced level of in-group collectivism (see 2.2.), this could explain Azerbaijan's stronger innovativeness at the regional and national level, albeit not primarily in the field of social innovation (section 3).

The comparative diagnostical method on CMM applied here for the first time has the advantage that even latent sub-structures can be extracted through a combination of deductive and inductive approaches to GABEK (see fig.5). This opens up promising possibilities for future research in the field (e.g. a CMM-extraction through a GABEK analysis of past and present secondary documents without time-consuming primary research). However, limitations arise from the fact that primarily experts have been interviewed 
and therefore only their reflected images of the actual, on-site CMM can be traced. Furthermore, the study did not fully flesh out the potentials of the GABEK-methodology, as the intertwinement of the CMM with moral and ethical judgments and values, prior experiences, emotional attitudes and goals (Argyris \& Schön, 1978; Mayring, 2008) could not be carried out for the sake of complexity-reduction. The same applies to the possibility of causal coding, which could be used in future studies for the full reconstruction of TIU and ETA (instead of their sub-structures as it was done here). These future studies could also make use of this potential to better separate societal values from practices (as realized in the GLOBE-study) and to shed more light on the interdependancies of national or regional culture with corporate/organizational culture. As the latter tends to be dominated by the former (House et al., 2004; Schmidt, 2005) this could open up promising insights into the dynamics of regional innovation systems and their governance (see Schuhbert, 2021a \& b).

While the discourse on the feasibility of successfully targeted interference in organizational culture can and shall not be opened here, it is clear that the CMM described in this study - together with the ideal typical models from fig. 1 and 3 - provide a basis for a set-actual comparison and thus delivers a promising starting point for a systematical, culture-compatible and incremental change-management (e.g. through awareness trainings).

\section{Conclusion}

This comparative study contributed to discussing culturally-shaped mental models as the primary substance of innovative knowledge in a tourist destination. On the special case of sustainable tourism development in two DC destinations, the effects of culture on the formation of CMM could be analyzed and major similarities and differences could be highlighted before the background of the GLOBE-model and the conceptual framework of the knowledge-creating destination. Even though the study ultimately cannot substitute a complete ethnography, the results suggest that the CMM in the Napo case are better suited to support the ideals of sustainable regional development. Despite the relative advantages that the Azerbaijani case has with regard to absorptive and innovative capacities, the Ecuadorian case incorporates a stronger socio-cultural focus on community integration, consensus building and open communication. This is required to trigger the local creation and not just the adoption of idiosyncratic social innovation.

To this end, as evidence from complementary studies indicate (Schuhbert 2021a \& b), it will be necessary to promote the emergence of appropriate cognitive social capital within a destination. This can be achieved through the optimization, synchronization and spread of social innovation-friendly CMM among its' core-actors. Cognitive social capital management could consequently combine a cultural engineering approach (targeted optimization of CMM) with network-management approaches (synchronization and distribution of CMM). Findings from the Azerbaijani case suggest, that optimal conditions can be provided by network cultures that effectively balance power and trust in juxtaposed formal and informal relationships. However, these channels can only serve as effective pipelines for transfer and conversion of knowledge, if appropriate cognitive social capital is given (Schuhbert, 2021a \& b). The individual strengths and weaknesses of the respective destinations' knowledgebases can serve as a starting point for more extensive mental modelling of destinations worldwide. This could help improve the above theoretical and methodological basis, could help to help to indicate promising intervention-paths and finally clarify if a systematic cultural engineering towards a more sustainable action-orientation is feasible.

Due to the similarities of the cases brought to light here, the difficulties observed in Napo today could also serve Guba and other UMIC to avoid some unsustainable developments. Ultimately, this requires this kind of a targeted change management to successfully integrate and mentally connect the sustainable tourism concept with other primary engrams.

\section{Bibliography}

Argyris, Ch, \& Schön, D. 1978. Organizational Learning: A Theory of Action Perspective. Reis: Revista española de investigaciones sociológicas, 77-78 (1997), 345-350.

Bachinger, M., Kofler, I. \& Pechlaner, H. 2020. Sustainable instead of high-growth? Entrepreneurial Ecosystems in Tourism. Journal of hospitality and tourism management, 44 (2020), 238-242.

Binder, P. 2017. A network perspective on organizational learning research in tourism and hospitality: A systematic literature review. International Journal of Contemporary Hospitality Management, 31(7), $2602-2626$.

Central Intelligence Agency 2021a. Azerbaijan, https://www.cia.gov/the-world-factbook/countries/azerbaijan $(15 / 12 / 21)$. 
Central Intelligence Agency 2021b. Ecuador, https://www.cia.gov/the-world-factbook/countries/ecuador $(15 / 12 / 21)$.

Cohen, W.M. \& Levinthal D.A. 1990. Absorptive capacity: A new perspective on learning and innovation. Administrative Science Quarterly, 35 (1), 128 - 153.

Döpfer, B., Habisch, A., Pechlaner, H., Poppe, X.-I., Schwarz, Christoph 2016. Entrepreneurship, shared values and the region - assessing the conditions for regional social performance of entrepreneurial behaviour. International journal of innovation and regional development : IJIRD. 7 (2016), 36-56.

EIU, Economist Intelligence Unit. Democracy Index 2019, https://www.eiu.com/topic/democracy-index (10/06/20).

Fischer, E. 2009. Das kompetenzorientierte Management der touristischen Destination: Identifikation und Entwicklung kooperativer Kernkompetenzen. Wiesbaden: Gabler.

Friedrich, P. \& Diamond, N. (Eds.)1994. Encyclopedia of World Cultures - Volume VI. New York: G.K. Hall.

Fuchs, M. \& Baggio, R. 2017. Creativity and Tourism Networks: A Contribution to a Post Mechanistic Economic Theory. Critical Tourism Studies Conference, Palma de Mallorca (June 25-29, 2017).

GLOBE 2020. An overview of the 2004 study, https://globeproject.com/study_2004_2007? page_id=data\#data $(09 / 12 / 20)$.

Gretzel, U., Werthner, H., Koo, C. and Lamsfus, C. 2015. Conceptual foundations for understanding smart tourism ecosystems. Computers in Human Behavior, 50, 558-563.

Hidalgo, C. \& Hausmann, R. 2009. The Building Blocks of Economic Complexity. Proceedings of the National Academy of Sciences. PNAS. 106 (26), 10570-10575.

Hjalager, A.-M. 2010. A review of innovation research in tourism. Tourism Management, 31(2010), 1-12.

Hofstede, G. 2001. Culture's Consequences. Comparing Values, Behaviours, Institutions and Organisations Across Nations. Thousand Oaks.

Hollstein, B. 2019. What Autobiographical Narratives Tell Us About the Life Course. Contributions of Qualitative Sequential Analytical Methods. Advances in Life Course Research, Vol 41.

House, R, Hanges, P., Javidan, M., Dorfman, P. and Gupta, V. 2004. Culture, Leadership and Organi-zations: The Globe Study of 62 Societies. Thousand Oaks.

Jafari, J. 2001. The scientification of tourism. In V. Smith \& M. Brent (Eds.), Hosts and Guests Revisited: Tourism Issues of the 21st Century (pp. 28-41). New York: Cognizant Communication Corporation.

Karimov, R. 2015. Development of non-oil sector in Azerbaijan: Tendencies and opportunities. Journal of Business \& Economic Policy, 2(2), 39-52.

Kluckhohn, F.R. \& Strodtbeck, F.I. 1961. Variations in Value Orientations. Evanston, Illinois: Row, Peterson.

Klimecki, R.G. \& Probst, G.J.B. 1990. Entstehung und Entwicklung der Unternehmenskultur. In: Lattmann, Ch. (eds.) (1990). Die Unternehmenskultur - Ihre Grundlagen und ihre Bedeu-tung für die Führung der Unternehmung (pp. 41-46). Heidelberg.

Kofler, I., Marcher, A., Volgger, M. \& Pechlaner, H. 2018. The special characteristics of tourism innovation networks : The case of the Regional Innovation System in South Tyrol. Journal of hospitality and tourism management. 37 (2018), 68-75.

Kutschker, M. \& Schmid, S. 2008. Internationales Management. Oldenbourg.

Lawler, O., Allan, H., Baxter, P., Castagnino, R., Corella Tor, M., Dann, L., Hungerford, J., Karmacharya, D., Lloyd, T., López-Jara, M., Massie, G., Novera, J., Rogers, A., Kark, S. 2021. The COVID-19 pandemic is intricately linked to biodiversity loss and ecosystem health. The Lancet, 5 (11), 840-850.

Lejarraja, I. \& Walkenhorst, P. 2007. Diversification by deepening linkages with tourism. In Proceedings of the World Bank Workshop on Export Growth and Diversification: Pro-Active Policies in the Export Cycle. Washington DC.

Mayring, P. 2008. Qualitative Inhaltsanalyse: Grundlagen und Techniken (10.Ed.). Pädagogik. Beltz.

Mirtsch, M., Pohlisch, J. \& Blind, K. 2020. International Diffusion of the Information Security Management System Standard ISO/IEC 27001: Exploring the Role of Culture. Proceedings of the 28th European Conference on Information Systems (ECIS), An Online AIS Conference, June 15-17, 2020.

Mosedale, J. \& Voll, F. 2017. Social Innovations in Tourism: Social Practices Contributing to Social Development. In: Sheldon, P. \& Daniele, R. (eds.) (2017). Social Entrepreneurship and Tourism: Philosophy and Practice. Springer.

Muñoz Barriga, A. 2014. Governance and Management of Tourism in two Biosphere Reserves in Ecuador: Galapagos and Sumaco. Greifswald.

Nonaka, I. \& Takeuchi H. 1995. The knowledge creating company: how Japanese companies create the dynamics of innovation. Oxford.

Nunkoo, R. 2017. Governance and Sustainable Tourism: What is the Role of Trust, Power and Social Capital? Journal of Destination Marketing and Management, 6 (2017), 277-285.

Ozseker, D. 2018. Towards a model of destination innovation process: an integrative review. The Service Industries Journal, 39(3/4), 206-228.

Pechlaner, H., Kozak, M. \& Volgger, M. 2014. Destination leadership: a new paradigm for tourist destinations? Tourism review : the official journal of the AIEST. 69 (2014), 1-9. 
Pechlaner, H. \& Bachinger, M. 2010. Knowledge networks of innovative businesses: an explorative study in the region of Ingolstadt. The service industries journal, 30 (2010), 1737-1756.

Pechlaner, H., Herntrei, M., Pichler, S. \& Volgger, M. 2012. From destination management towards governance of regional innovation systems - the case of South Tyrol, Italy. Tourism review : the official journal of the AIEST. 67 (2012), 22-33.

Pechlaner, H. \& Volgger, M. 2012. How to promote cooperation in the hospitality industry. International Journal of Contemporary Hospitality Management - Special Issue Qualitative Research in Hospitality and Tourism, 24(6), 925-945.

Pechlaner, H., Thees, H., Olbrich, N. \& Schuhbert, A. 2020. The Living Lab as a Tool to Promote Residents' Participation in Destination Governance. Sustainability, 12, 1120.

Pinillos, M.-J. \& Reyes, L. 2011. Relationship between Individualist-Collectivist Culture and Entre-preneurial Activity: Evidence from Global Entrepreneurship Monitor Data, Small Business Economics, 37, 23-37.

Probst, G.; Raub, S. \& Romhardt, K. 1999. Managing knowledge; Wiley \& Sons

Raich, F. 2006. Governance räumlicher Wettbewerbseinheiten: Ein Ansatz für die Tourismus-Destination. Wirtschaftswissenschaft. Deutscher Universitäts-Verlag/GWV Fachverlage GmbH, Wiesbaden.

Roberts, N., Galluch, P.S., Dinger, M. \& Grover, V. 2012. Absorptive Capacity and Information Systems Research: Review, Synthesis, and Directions for Future Research. MIS Quarterly, 36(2), 625-648.

Rook, L. 2013. Mental models: A robust definition. The Learning Organization, 20(1).

Schmidt, S.J. 2005. Unternehmenskultur: Die Grundlage für den wirtschaftlichen Erfolg von Unternehmen. Weilerswist.

Schuhbert, A. 2013. Touristische Destinationen als Cluster - Eine Untersuchung zur wissensbasierten Wettbewerbsfähigkeit tourismusökonomischer Raumsysteme in Entwicklungsländern am Beispiel der Napo Provinz Ecuadors, Trier.

Schuhbert, A. 2018. Ländliche Regional- und Destinationsentwicklung als Diversifikationsstrategie - am Beispiel ausgewählter Emerging Economies in Asien und Lateinamerika. Zeitschrift für Tourismuswissenschaft, 10(2), 233-265.

Schuhbert, A., Thees, H., Herbold, V., Weinreiter, J. \& Kantsperger, M. 2020. Cultural tourism routes as incubators for innovation and economic diversification: A potential analysis in the framework of the New Silk Route Initiative in Azerbaijan. Zeitschrift für Wirtschaftsgeographie, 64(4). 211-232.

Schuhbert, A. 2021a. From Network-Pools to Activated Networks - A Conceptual Approach on Absorptive Capacities in a Rural Destination of Azerbaijan. Journal of Information and Knowledge Management, 02/2021 (in press).

Schuhbert, A. 2021b. Specifying Destination-Based Networks by Governance-Mode: A Social Capital Approach to Innovative Capacity in a Rural Destination of Azerbaijan. Tourism Planning and Development, DOI: 10.1080/21568316.2021.1953119.

Thomas, R. \& Wood, E. 2015. The absorptive capacity of tourism organisations. Annals of Tourism Research, $54,84-99$.

Trunfio, M. \& Campana, S. 2019. Drivers and emerging innovations in knowledge based destinations: Towards a research agenda. Journal of Destination Marketing \& Management, 14(2019).

Volgger, M., Pechlaner, H. \& Pichler, S. 2017. The practice of destination governance : a comparative analysis of key dimensions and underlying concepts. Journal of Tourism, Heritage \& Services Marketing : JTHSM. 3 (2017), 18-24.

WEF, World Economic Forum 2015-2020a. Global Competitiveness Report.Geneva.

WEF, World Economic Forum 2015-2020b. Travel and Tourism Competitiveness Report.Geneva.

Wilbert, J. (Ed.) 1994. Encyclopedia of World Cultures - Volume VII. New York.

Zhao, X., Rauch, A. \& Frese, M. 2012. Cross-country Differences in Entrepreneurial Activity: The Role of National Cultural Practice and Economic Wealth. Frontiers of Business Research in China, 6(4).

\section{Notes}

1 Due to the congruence, both capability-subsets are treated as integrated elements here.

Recibido: 


\section{Appendix}

Figure 9: Research Design

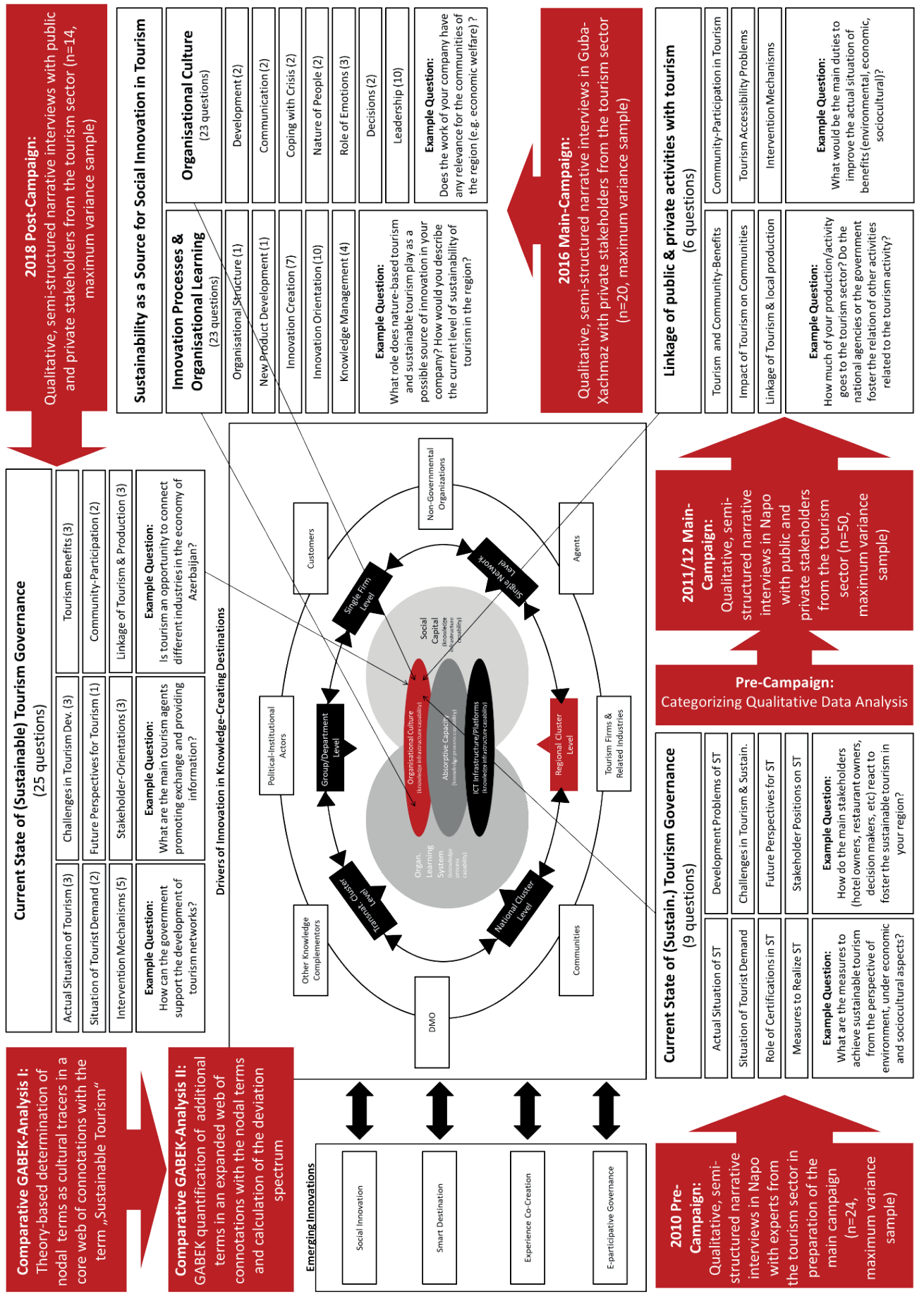


Figure 10: Overview on selected GLOBE criteria (adapted from House et al, 2004)

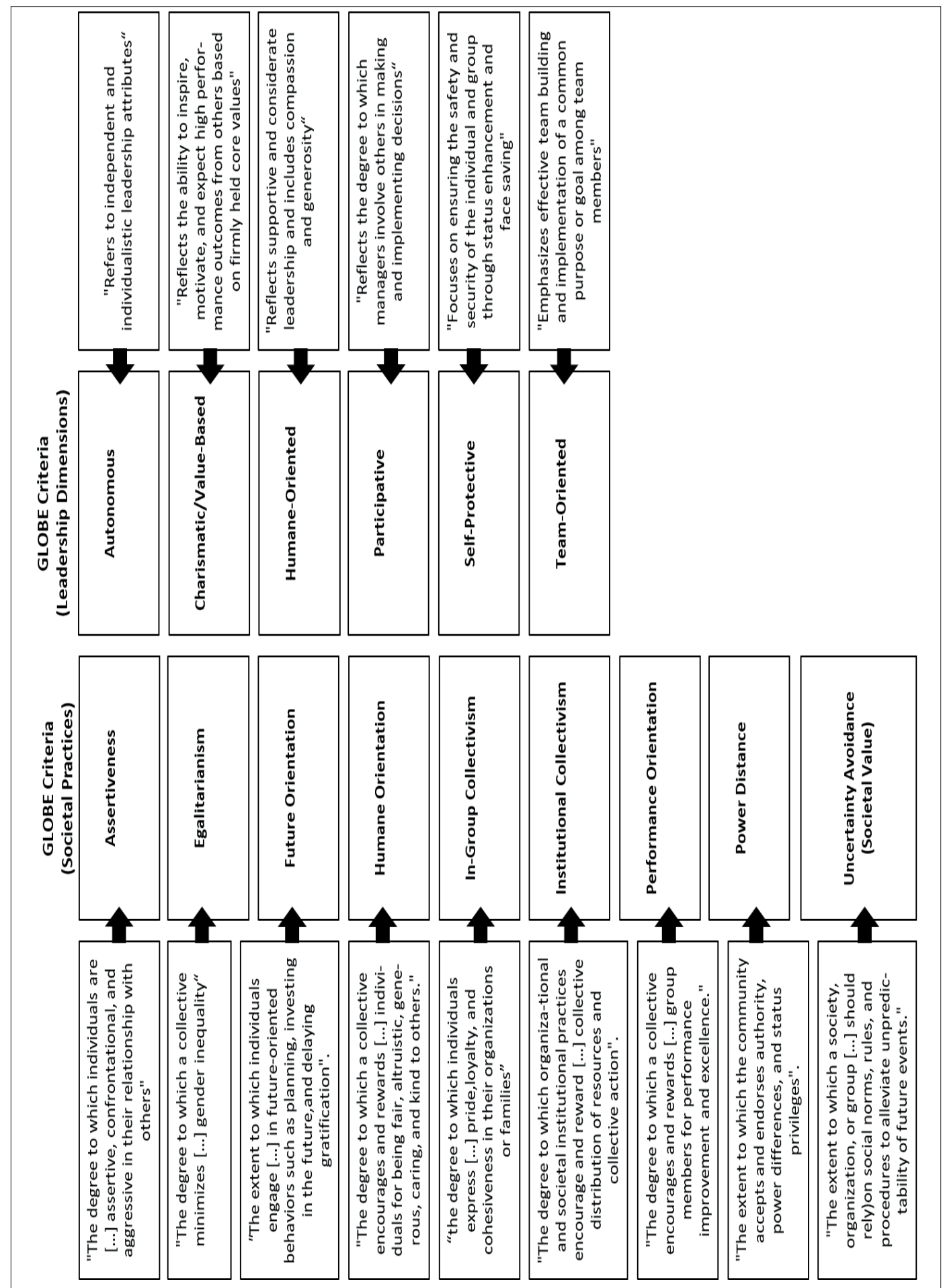

